\title{
Corrigendum: Vogus et al., PEPFAR Transitions to Country Ownership: Review of Past Donor Transitions and Application of Lessons Learned to the Eastern Caribbean
}

Abigail Vogus, Kylie Graff

Cee original article: Abigail Vogus and Kylie Graff 3(2): 281 .

In the article "PEPFAR Transitions to Country Ownership: Review of Past Donor Transitions and Application of Lessons Learned to the Eastern Caribbean" by Abigail Vogus and Kylie Graff, which appeared in the June 2015 issue (Volume 3, Issue 2), on page 281 , sixth sentense in first paragraph under
"Institutionalized Processes" section has been changed from "Bennett et al. are evaluating a PEPFAR-funded program in India where management shifted from NGOs to the government." to "Bennett et al. are evaluating a program in India, supported by the Bill and Melinda Gates Foundation, where management shifted from NGOs to the government.".

The article has been corrected accordingly.

Received: 2014 December 4; Accepted: 2015 April 3

Citation of original article: Vogus A, Graff K. PEPFAR transitions to country ownership: review of past donor transitions and application of lessons learned to the eastern caribbean. Glob Health Sci Pract. 2015;3(2):274-286. http://dx.doi.org/10.9745/GHSP-D-14-00227.

abt Associates, Inc, Bethesda, MD, USA.

Correspondence to Kylie Graff (Kylie_Ingerson@abtassoc.com). 